\title{
Hiring internationally educated nurses in hospitals: role of competition and resource availability
}

\author{
Shivani Gupta*1, Josue Patien Epane ${ }^{2}$, Robert Weech-Maldonado ${ }^{1}$ \\ ${ }^{1}$ University of Alabama at Birmingham, Birmingham, Alabama, USA \\ ${ }^{2}$ University of Nevada, Las Vegas, Nevada, USA
}

Received: October 19, 2014

DOI: $10.5430 /$ jha.v4n3p79
Accepted: November 25, $2014 \quad$ Online Published: May 6, 2015

URL: http://dx.doi.org/10.5430/jha.v4n3p79

\begin{abstract}
Objective: This study used Porter's Five Forces Model and the Resource Dependence Theory (RDT) to examine the association of competition and other market factors with the hospital's decision to hire internationally educated nurses.

Methods: A panel design was used comprising a national sample of nonfederal, acute care hospitals $(n=4,116)$ in the United States. Data, for the years 2008-2012, were derived from American Hospital Association's Annual Survey and Area Health Resource File. Logistic regression with hospital random effects and state and year fixed effects was conducted to test the above mentioned association.

Results: The study findings suggest that hospitals hire internationally educated nurses as a strategy to meet their staffing needs in more competitive and diverse markets. Moreover, hospitals that hire internationally educated nurses are system-affiliated, larger, and see more Medicare patients than those that do not hire them.

Conclusions: Findings of this study could help health care managers to understand the influence of market factors on utilization of internationally educated nurses to fulfill their hospitals' nurse staffing needs. Furthermore, the study findings can inform policymakers in crafting policies on the use of internationally educated nurses as a strategy to address nursing shortages.
\end{abstract}

Key Words: Internationally educated nurses, Market factors, Competition, Porter's five forces model

\section{INTRODUCTION}

Health care organizations in the United States have been facing a cyclical shortage of nurses for many years. ${ }^{[1]}$ In the year 2000, the national supply of full-time equivalent (FTE) registered nurses (RNs) was estimated at 1.89 million whereas the demand was estimated at two million, causing a shortage of 110,000 nurses $(6 \%) .{ }^{[2,3]}$ While the recent shortage seems to have eased as many nurses returned to work during the great recession, it is projected that the demand for RNs will soon surpass their supply. ${ }^{[4,5]}$ The projected shortage of nurses is estimated to increase to $260,000 \mathrm{RNs}$
FTEs by year 2025 even though the supply of RNs FTEs would reach approximately 2.8 million in $2025 .{ }^{[4]}$

The current nursing shortage is attributed in part to an increase in demand for health care from aging baby boomers. ${ }^{[6]}$ Other potential contributors to this shortage include an aging nursing workforce and inadequate investment into creating a sustainable workforce. ${ }^{[2,4-6]}$ This lack of resources is resulting in insufficient numbers of new nursing graduates entering the labor market every year. ${ }^{[7]}$ Thus, creating an imbalance between the number of nurses entering the workforce and the number approaching retirement.

\footnotetext{
*Correspondence: Shivani Gupta; Email: sgupta9@uab.edu; Address: Department of Health Services Administration, University of Alabama at Birmingham, 1720 2nd Ave. S., SHPB 552, Birmingham, Alabama, 35294, USA.
} 
One of the most common strategies employed by U.S. hospitals to address nursing shortages has been hiring nurses from other countries, ${ }^{[8]}$ also referred to as "Internationally Educated Nurses" (IENs). Xu and Kwak ${ }^{[9]}$ define IENs as a registered nurse with an active license to practice nursing in the United States, who obtained his or her basic nursing education in another country. The terms "Foreign educated nurses" and IENs have been used synonymously in the literature. Therefore, these two terms are used interchangeably for the purpose of this study. According to the National Sample Survey of Registered Nurses (NSSRN), there were approximately 165,539 IENs in United States in 2008, of which 146,097 were employed in nursing. This represented approximately $5.6 \%$ of the RNs workforce, ${ }^{[10]}$ a $2.1 \%$ increase from 2007. ${ }^{[11]}$

Since IENs have become an integral part of the nursing workforce ${ }^{[12]}$ considerable research has focused on various issues involving migration of nurses such as acculturation, ${ }^{[13]}$ contract issues, licensure ${ }^{[14]}$ and the immigration process. ${ }^{[15]}$ The characteristics that differentiate IENs from U.S. nurses have also been studied extensively over the years. Previous research shows that IENs were not only younger and educationally better prepared, but were also more experienced as nurses. ${ }^{[9]}$ They earned more by working longer hours, when compared to U.S. educated nurses; for instance, in 2004, $81.5 \%$ of IENs worked full-time as compared to $70.9 \%$ U.S nurses. ${ }^{[16]}$ They were primarily employed in urban hospitals, as staff nurses (76.1\% IENs vs. $61.8 \%$ U.S. nurses) and in positions with direct contact to patients $(71.1 \%$ IENS $v s$ $54 \%$ U.S. nurses). ${ }^{[9,16,17]}$ However, there is little literature examining the contextual factors that might influence the hospitals' decision to hire IENs. Cho, Masselink, Jones, and Mark $^{[18]}$ examined the role of geographic and community characteristics in the hiring decision by acute-care hospitals. They found that hospitals located in counties with older and ethnically diverse populations were more likely to hire IENs. ${ }^{[18]}$ However, the authors did not consider the role of competition and other market factors in the hospitals' hiring decision.

This study contributes to the literature by examining the association of competition and other market factors with the hospitals' decision to hire IENs. Previous studies have shown that staffing levels are significantly associated with both quality of care $^{[19,20]}$ and hospitals' financial performance. ${ }^{[21]}$ Therefore, recruitment of IENs could have a considerable impact on the quality of care and financial performance of hospitals utilizing IENs. Findings of this study could help health care managers to understand the influence of market factors on utilization of IENs to fulfill hospitals' nurse staffing needs. This understanding would allow hospitals' managerial teams to make better-informed decisions in terms of hiring IENs in response to market forces as well as ensuring adequate nurse staffing to deliver high quality of care.

\section{Conceptual Framework}

Nursing workforce is one of the most important resources for hospitals. ${ }^{[21]}$ Factors that affect the availability of this resource could impact hospitals' behavior related to hiring of nurses. This study utilizes Resource dependence theory $(\mathrm{RDT})^{[22]}$ and Porter's five forces model ${ }^{[23]}$ to analyze factors other than market labor shortage, which could influence hospitals' hiring behavior (see Figure 1).

According to RDT, organizations are not self-sufficient and depend on their environment for supply of resources critical to their survival. ${ }^{[2]}$ The extent of an organization's dependence on its environment depends on the importance of the resources, number of sources for the supply of resources and the number and relative power of organizations competing for the resource. ${ }^{[22]}$ Therefore, environmental forces can affect an organization's behavior by influencing the supply of resources necessary for its operations. ${ }^{[24]}$ Hospitals tend to compete on the basis of quality of care, given that it matters to their patients. ${ }^{[25]}$ Since RNs staffing is significantly associated with the quality of care ${ }^{[20]}$ as well as financial performance of hospitals, especially in competitive markets, ${ }^{\text {[21] }}$ RNs represent a critical resource for hospitals. Decreased availability of RNs could influence hospitals' ability to provide high quality of care. Therefore, hospitals' behavior to seek alternative sources of RNs could be motivated by the need to secure a consistent supply of nurses in order to deliver high quality of care and maintain their competitive advantage.

The extent of direct interaction between the organization and its environment could be categorized into: first involving environmental elements involved in direct exchange with the organizations (customers and suppliers) and second involving the elements competing with the organization for the resources being directly exchanged (patients) and is influenced by the number and size of competitors. ${ }^{[26]}$ Porter's five forces model provides a framework to analyze the industry environment and its competitive structure ${ }^{[23]}$ that could influence the direct interaction between an organization and its environment, thereby affecting the organization's behavior i.e. hospitals' hiring decisions. According to Porter, ${ }^{[23]}$ firms within an industry compete to achieve sustained competitive advantage. Five forces, namely threat of new entrants, bargaining power of the buyers, threat of substitute products or services, bargaining power of the suppliers and rivalry among existing firms, act in synergy to determine the competitive interactions within an industry and affect the competitive 
advantage enjoyed by the firms in that industry. ${ }^{[27]}$

Threat of new entrants refers to the ease with which new firms can enter an industry (market) and compete with incumbent firms for market share and resources. ${ }^{[27]}$ The increased competition for resources introduces new pressures in the market. However, the threat of new entrants depends on the amount and strength of barriers to entry. ${ }^{[27]}$ Markets with high entry barriers and low exit barriers have low levels of competition since it is difficult for new firms to enter the market, but they can exit from the market easily. Government policies, such as certificate of need (CON), can aid in or hinder new entry into the market by influencing the strength of the entry barriers. ${ }^{[28]}$

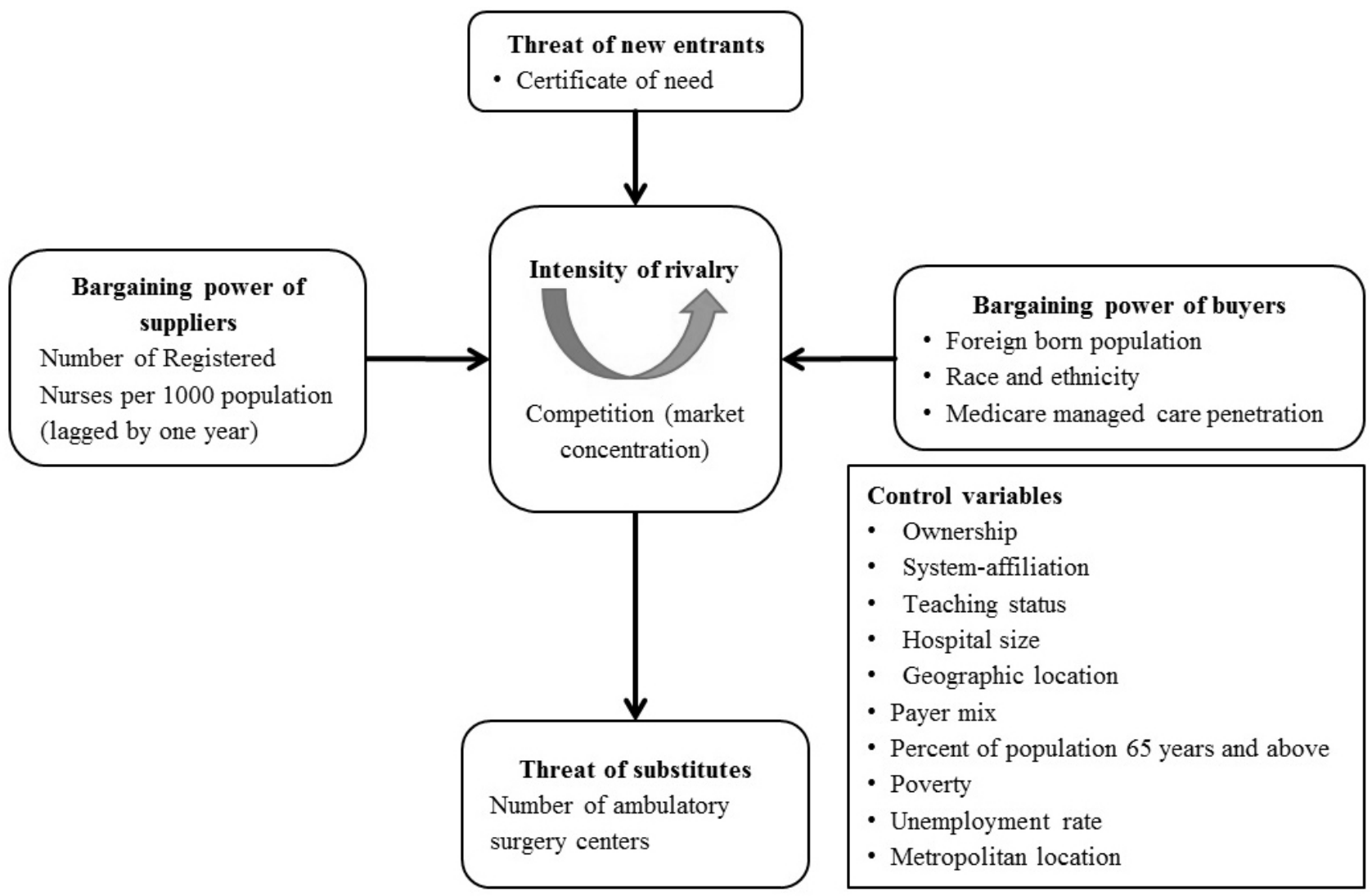

Figure 1. Model for factors influencing the hospitals' decision to hire internationally educated nurses

In states with active $\mathrm{CON}$ laws, hospitals are required to demonstrate that a clinically legitimate need for care could not be met by current providers and that there is a need for new entrants into the market or for expansion by current providers. ${ }^{[29]}$ Therefore, CON laws can lower the threat of new entrants by creating a barrier to entry for new providers and reduce market competition. Consequently, hospitals located in states with active CON laws face less competition for a limited supply of resources such as RNs. We, therefore, hypothesize that:

Hypothesis 1. Hospitals located in states with active CON laws are less likely to hire IENs.

Bargaining power of the buyers refers to the extent to which the customers in an industry can extract terms (prices or quality) advantageous to them by pressurizing the sellers.
In healthcare, unlike other industries, consumers (patients) do not pay the full costs of the services they receive. ${ }^{[25]}$ Third-party payers, both public (Medicare and Medicaid) and private insurance companies make majority of the payments. ${ }^{[30]}$ Therefore, both patients and insurers represent the buyers of healthcare services and can influence hospitals' behavior in terms of quality of care delivered.

Cho et al. ${ }^{[18]}$ found that the likelihood of hiring IENs increased when a hospital was located in counties with more ethnically diverse population. These results were attributed to perceptions of the hospital administrators related to the needs of the patient population they serve and the communities in which their hospitals operate and the perceived receptivity of the hospitals' communities and patient populations to IENs. In any industry, firms utilize valuable and unique resources to compete and achieve sustained competitive advantage and 
superior performance. ${ }^{[31]}$ Hiring IENs could be considered a unique, strategic resource employed by hospitals, operating in ethnically diverse markets and communities with higher numbers of foreign-born, to maintain their competitive advantage. Therefore, we hypothesize that:

Hypothesis $2 a$. Hospitals that service more ethnically diverse populations are more likely to hire IENs.

Managed care penetration in the hospital market could be considered another expression of buyer power. ${ }^{[28]}$ With an increasing number of Medicare beneficiaries enrolling in managed care plans, it has become an important source of referrals for hospitals. Approximately, 26.2\% of Medicare beneficiaries were enrolled in managed care plans in 2013 ${ }^{\text {[32] }}$ as compared to $15.4 \%$ in 2011. ${ }^{[33]}$ Managed care plans have greater bargaining power in the markets where there is greater managed care penetration. Furthermore, an external organization can influence an organization's behavior by making certain demands in return for continued supply of resources required for the organization's operations. ${ }^{[22]}$ Similarly, the power exercised by managed care plans would stem from their ability to make and enforce rules by controlling the referrals since referral volume directly influences hospitals' reimbursement. Therefore, managed care plans could potentially influence hospitals' behavior by seeking accommodations in terms of staffing levels and quality of care. ${ }^{[28]}$ Hospitals operating in such markets would seek ways of maintaining staffing levels such as hiring IENs to accommodate the needs of managed care plans.

Hypothesis 2b. Hospitals operating in markets with greater Medicare managed care penetration rates are more likely to hire IENs.

Threat of substitutes represents the extent to which another product or service could fulfill the buyers' needs by performing the same or a similar function as an industry product. ${ }^{[23]}$ Ambulatory Surgical Centers (ASCs) form one of the growing threats and compete with hospitals for ambulatory surgery patients. ${ }^{[34-36]}$ Research has shown that ASCs offer quality services at lower costs to patients. ${ }^{[37,38]}$ Since patients do not pay the full costs of services they receive, the switching cost for them is relatively low. ${ }^{[30]}$ Additionally, third-party payers are interested in less costly alternatives, which provide care of equivalent or better quality as hospitals, for their beneficiaries. ${ }^{[30]}$ Therefore, the threat of substitution for hospitals is high, especially for surgical services that may be provided in ambulatory settings. In order to maintain their competitive advantage, hospitals would need to provide superior quality of care to satisfy both payers and patients. However, quality of care has been shown to be highly correlated to the nurse-to-patient ratio. ${ }^{[19]}$ Therefore, hospitals may hire
IENs, as a strategy to meet their staffing needs and ensure delivery of high quality of care to compete with the ASCs. Moreover, both ASCs and hospitals would compete for the same pool of resources (RNs). ${ }^{[34]}$ Since, hospitals may have more resources at their disposal than ASCs, ${ }^{[39]}$ so they are more likely to invest in hiring IENs than ASCs. Therefore, we hypothesize that:

Hypothesis 3. Hospitals located in markets with a larger number of ambulatory surgery centers are more likely to hire IENs.

Another component of Porter's five forces model is the bargaining power of suppliers. This force represents the extent to which the suppliers could influence a firm by controlling the supply of critical inputs such as labor and raw materials. ${ }^{[27]}$ Hospitals' competitive position in the market is influenced by the availability of essential inputs or resources such as RNs. Supply of RNs to hospitals could be measured in terms of number of RNs with active licenses per 1,000 population. Inadequate investment into the infrastructure of nursing schools as well as a shortage of nursing faculty affect the number of new nursing graduates entering the labor pool every year. ${ }^{[4]}$ According to the American Association of College of Nursing's 2011 report, 75,587 qualified applicants were turned away by nursing schools from baccalaureate and graduate nursing programs due to an insufficient number of faculty, clinical sites, classroom space, and clinical preceptors, as well as budget constraints. ${ }^{[40]}$ As a result of inadequacy of the number of new nursing graduates entering the labor market, hospitals would need to look for alternative supply of RNs such as hiring IENs. Lower availability of RNs in the previous year would also prompt the hospitals to hire IENs in the next year. Therefore, in case of a nursing shortage, IENs would represent an important supplier of nursing labor force for hospitals. Therefore, we hypothesize that:

Hypothesis 4. Hospitals located in counties with lower numbers of RNs per 1,000 population are more likely to hire IENs.

Rivalry among existing firms determines the level of competition between firms already in the industry. ${ }^{[27]}$ Organizations in an industry, when operating in the same market, influence each other's action. ${ }^{[22]}$ They tend to compete for the same resources and hence employ various strategies to maintain their competitive advantage. The competitive strategies employed by hospitals are a function of their market concentration. ${ }^{\text {[28] }}$ The higher the market concentration of hospitals, the more competitive is the environment leading to greater demand on a shared pool of resources. ${ }^{[41]}$ For instance, multiple hospitals located in the same county compete for the same pool 
of RNs. The competition would intensify in the event of a shortage, and the hospitals would tend to utilize alternative sources for nursing supply such as hiring IENs.

Hypothesis 5. Hospitals located in markets with higher competition are more likely to hire IENs.

\section{METHODS}

\subsection{Sample}

The study sample consists of all nonfederal, U.S. medical/surgical, acute-care hospitals $(\mathrm{N}=4,116)$ between 2008 and 2012 for a total of 16,471 hospital-year observations. We excluded hospitals controlled by federal government such as military and veterans administration hospitals since the patient population they serve is different than that of other ownership types.

\subsection{Data}

Data were derived from two sources: the American Hospital Association (AHA) Annual Survey and the Area Health Resources File (AHRF). These data sets include information on organizational and market factors of hospitals. The AHA survey includes information about organizational characteristics. ${ }^{[42]}$ The AHRF data set contains county-level information on market characteristics such as Medicare Advantage penetration. ${ }^{[43]}$ The data included in AHRF is compiled from a variety of sources, including the AHA, the U.S. Bureau of Census, the Centers for Medicare and Medicaid Services, the U.S. Bureau of Labor and Statistics, and the National Center for Health Statistics. ${ }^{[43]}$

\subsection{Measures}

\subsubsection{Dependent variable}

Table 1 provides definitions of the dependent, independent and control variables included in the analyses and their sources of data. The dependent variable is dichotomous ( 1 = did hire; $0=$ did not hire IENs) and was constructed by combining the three response categories of "more", "less" and "equal" into one category - "did hire" and keeping the category "did not hire" as such from AHA. Hospitals select one of the above-mentioned four response categories in response to the question, "Did your facility hire more foreign-educated nurses to help fill RNs vacancies in 2008 versus 2007?" and so on for subsequent years in the AHA survey. Of the hospitals included in the study, only $11.79 \%$ hired IENs and $88.21 \%$ did not. Since, very few hospitals picked "less", "equal" and "more" as their answer to the above-mentioned question, these three categories were combined into one category (did hire) (see Table 1).

\subsubsection{Independent variables}

The independent variables include: whether state has CON National Conference of State Legislatures (NCSL), ${ }^{[4]}$ ethnic diversity in the county, Medicare managed care penetration in the county, number of ambulatory surgery centers in the county, supply of RNs per 1,000 population and competition in the market in which the hospital operated. Competition was operationalized using Herfindahl-Hirschman Index (HHI). Ethnic diversity was measured by the percentage of foreign born, Blacks, Hispanics, American-Indians, Asian/Pacific islanders and other races in the county. The variable RNs per 1,000 population was lagged by a year to assess the association of the lower proportion of RNs in the previous year with the hospitals' likelihood of hiring IENs in the next year.

\subsubsection{Control variables}

The market factors included as control variables were poverty, unemployment rate in the county, metropolitan location and percentage of people 65 and older in the county. Organizational factors included as control variables in the analysis were ownership, hospital size (number of staffed beds), system-affiliation, teaching status of hospital, geographic location (regional) and payer-mix measured as proportion of Medicare/Medicaid inpatient days. These factors (organizational and market) have been shown to influence nurse staffing in hospitals. ${ }^{[45-47]}$

\subsection{Analysis}

Descriptive analysis was performed to analyze the distribution of variables. Bi-variate analysis, using chi-square for categorical and $t$-test for continuous variables, was conducted to assess the differences in organizational and market characteristics of hospitals, which hired IENs versus those that did not. Finally, a logistic regression with hospital random effects, and state and year fixed effects was done using a panel design to examine the association of competition and other market factors with the hospitals' hiring decision. The random effects model accounts for the correlation of repeated hospital observations over time. SAS 9.3 and STATA 12 were used to conduct the analyses.

\section{Results}

\subsection{Descriptive statistics}

The study sample consisted of approximately 4,116 shortterm, acute-care hospitals per study year of which $11.79 \%$ hospitals hired IENs. More than half of the hospitals in the sample were located in a metropolitan area $(55.55 \%)$ and were part of a system $(55.28 \%)$. The mean number of hospital beds in the sample was 161. Medicare, on average, formed $50.69 \%$ of the payer mix of the hospitals in the study sample 
while Medicaid formed only $18.85 \%$. Similarly, $37.89 \%$ of the hospitals were located in the south, and $19.09 \%$ were in the west census region. The mean HHI for the hospitals in the sample was 0.70 indicating low levels of competition On average, $14.45 \%$ of the population in the counties, in which the hospitals operated, was 65 years and older, while $10.22 \%$ were non-Hispanic Blacks, $13.14 \%$ were Hispanics and $1.25 \%$ were non-Hispanic American-Indians.

\subsection{Bi-variate statistics}

Bivariate analysis showed that the hospitals that did not respond (28\%) were not significantly different in their organizational and market characteristics from those that did respond. However, the bi-variate analysis (see Table 2) showed that there are statistically significant differences be- tween the market characteristics of the hospitals that hired IENs versus those that did not. For instance, hospitals hiring IENs were located in counties with more ethnically diverse populations in terms of percentage of foreign-born (13.2\%), Whites (59.3\%), Blacks (14.0\%), Hispanics (18.8\%), American-Indians (1.2\%), and Asian/Pacific-islanders (4.6\%). Furthermore, hospitals hiring IENs were located in markets characterized by higher competition, greater Medicare managed care penetration, a larger number of ambulatory surgery centers, greater supply of RNs per 1,000 population, and a lower percentage of the population 65 years and older. Moreover, hospitals that hire IENs are, on average, larger, are located in a metropolitan area and see more Medicare patients than those that do not hire IENs.

Table 1. Definition and data source of dependent; independent and control variables

\begin{tabular}{|c|c|c|}
\hline Variables & Variable Definition & Source \\
\hline \multicolumn{3}{|l|}{ Dependent Variable } \\
\hline Hire & $\begin{array}{l}\text { A dichotomous variable representing the hospitals' decision to hire internationally educated nurses } \\
\text { (IENs) }(1=\text { yes; } 0=\text { No) }\end{array}$ & AHA $^{*}$ \\
\hline \multicolumn{3}{|l|}{ Independent Variables } \\
\hline Certificate of Need & Do states in which hospitals operate have Certificate of Need? & Literature \\
\hline Foreign-born population & Percent of foreign-born population in the county & \multirow{10}{*}{ AHRF $^{* *}$} \\
\hline Percent of Whites & Ratio of Whites over census population; multiplied by 100 & \\
\hline Percent of Blacks & Ratio of Blacks over census population; multiplied by 100 & \\
\hline Percent of Hispanics & Ratio of Hispanics over census population; multiplied by 100 & \\
\hline Percent of American-Indians & Ratio of American-Indians over census population; multiplied by 100 & \\
\hline Percent of Asian / Pacific Islanders & Ratio of Asian and Pacific Islanders over census population; multiplied by 100 & \\
\hline Percent of Other races & Ratio of other races over census population; multiplied by 100 & \\
\hline Medicare managed care penetration & Ratio of Medicare managed care enrollees over Medicare eligible in the county; multiplied by 100 & \\
\hline Ambulatory Surgery Centers & Number of ambulatory surgery centers in the county & \\
\hline $\begin{array}{l}\text { Registered Nurses Per } 1,000 \\
\text { population }\end{array}$ & Number of Registered Nurses with active licenses over Total Population; multiplied by 1000 & \\
\hline $\begin{array}{l}\text { Competition (Market Concentration; } \\
\text { HHI) }\end{array}$ & $\begin{array}{l}\text { HHI values ranged from } 0 \text { to } 1 ; 1 \text { indicating monopolistic markets and values close to } 0 \text { indicating } \\
\text { highly competitive markets. Market share was calculated as the proportion of a hospital's inpatient } \\
\text { days to total market inpatient days. HHI was calculated as the sum of squares of individual hospital's } \\
\text { market share in the health service area (HSA) using total hospital inpatient days. }\end{array}$ & AHA, AHRF \\
\hline \multicolumn{3}{|l|}{ Control Variables } \\
\hline Older population & Percent of population 65 years and above over census population; multiplied by 100 & \multirow{5}{*}{ AHRF } \\
\hline Poverty & Percent of population in poverty & \\
\hline Unemployment Rate & Unemployment rate 16 years and above & \\
\hline Geographic location & Hospital was located in a metropolitan area or not $(1=$ yes; $0=$ No $)$ & \\
\hline Regional Location & Census regional location of hospitals & \\
\hline Ownership & Ownership status was measured as Nonprofit, For-Profit, and non-federal Government & \multirow{5}{*}{ AHA } \\
\hline System-affiliation & $\begin{array}{l}\text { System affiliation is a dichotomous variable indicating whether a hospital belonged to a hospital } \\
\text { system or not }(1=\text { yes; } 0=\text { No) }\end{array}$ & \\
\hline Teaching status & $\begin{array}{l}\text { Hospital is a member of the Council of Teaching Hospitals of the Association of American Medical } \\
\text { Colleges or not }(1=\text { yes; } 0=\text { No) }\end{array}$ & \\
\hline Hospital Size & Number of staffed beds & \\
\hline $\begin{array}{l}\text { Proportion of Medicare Inpatient } \\
\text { days }\end{array}$ & Total hospital Medicare inpatient days divided by total hospital inpatient days & \\
\hline
\end{tabular}

" AHA: American Hospital Association Annual Survey of Hospitals; ${ }^{* *}$ AHRF: Area Health Resource File 
Table 2. Bi-variate analysis of market and organizational characteristics

\begin{tabular}{|c|c|c|c|}
\hline \multirow{2}{*}{ Description } & \multicolumn{2}{|c|}{ Mean/Frequencies } & \multirow{2}{*}{ p-values } \\
\hline & Hire $(11.79 \%)$ & Did not hire $(88.21 \%)$ & \\
\hline \multicolumn{4}{|l|}{ Market Characteristics } \\
\hline Medicare managed care penetration & $21.54 \%$ & $18.61 \%$ & .023 \\
\hline Foreign-born & $13.21 \%$ & $6.79 \%$ & .001 \\
\hline Whites & $59.27 \%$ & $75.13 \%$ & .001 \\
\hline Blacks & $14.02 \%$ & $8.98 \%$ & .001 \\
\hline Hispanics & $18.76 \%$ & $10.73 \%$ & .001 \\
\hline American-Indians & $1.19 \%$ & $1.11 \%$ & .001 \\
\hline Asian / pacific Islanders & $4.62 \%$ & $2.27 \%$ & .001 \\
\hline Other races & $0.12 \%$ & $0.17 \%$ & .001 \\
\hline Competition ((Market Concentration; Hirschman-Herfindahl Index) & 0.546 & 0.736 & .001 \\
\hline Number of Ambulatory Surgery Centers & 19.12 & 7.40 & .001 \\
\hline Population 65 years and older & $12.75 \%$ & $14.80 \%$ & .001 \\
\hline Hospitals located in Metropolitan area & $23.47 \%$ & $76.53 \%$ & .001 \\
\hline Population in poverty & $15.60 \%$ & $15.31 \%$ & .001 \\
\hline Unemployment Rate & 7.65 & 7.62 & .001 \\
\hline \multicolumn{4}{|l|}{ Organizational Characteristics } \\
\hline For-profit hospitals & $20.62 \%$ & $79.38 \%$ & .001 \\
\hline Not-for-profit hospitals & $17.61 \%$ & $82.39 \%$ & .001 \\
\hline Non-federal Government hospitals & $10.80 \%$ & $89.20 \%$ & .001 \\
\hline System-affiliated hospitals & $18.87 \%$ & $81.83 \%$ & .001 \\
\hline Teaching status & $33.94 \%$ & $66.06 \%$ & .001 \\
\hline Hospitals in the Northeast census region & $19.12 \%$ & $80.88 \%$ & .001 \\
\hline Hospitals in the Midwest census region & $10.31 \%$ & $89.69 \%$ & .001 \\
\hline Hospital Size (Number of Staffed Beds) & 265.3 & 152.7 & .001 \\
\hline Proportion of Medicare Inpatient Days & $48.87 \%$ & $51.22 \%$ & .001 \\
\hline Proportion of Medicaid Inpatient Days & $19.76 \%$ & $18.52 \%$ & .001 \\
\hline
\end{tabular}

Note. 4,116 average number of hospitals / year observations (2008-2012)

\subsection{Logistic regression}

Results of the logistic regression analysis (as odds ratios $[\mathrm{OR}]$ ), show that hospitals operating in more ethnically diverse markets have greater odds of hiring IENs. However, percent of foreign-born and Medicare managed care penetration were not statistically significant. Thus, hypothesis 2 is partially supported. Furthermore, hospitals operating in markets with higher levels of competition have greater odds of hiring IENs thereby supporting hypothesis 5. Location of the hospital in a state with CON, number of ambulatory surgery centers in the market, and number of RNs per 1,000 population lagged by one year did not have a statistically significant association with the hospitals' hiring decision. Therefore, hypotheses 1, 3 and 4 were not supported.

Among the control variables, larger, and system-affiliated hospitals as well as those that see greater proportion of Medicare patients have greater odds of hiring IENs. Similarly, hospitals located in metropolitan areas have greater odds of hiring IENs. However, no statistically significant differ- ence was found between the hiring behavior of not-for-profit, nonfederal government and for-profit hospitals while population 65 or above in the county was marginally significant. Detailed results are presented in Table 3.

\section{Discussion}

U.S. hospitals have repeatedly faced shortage of RNs. Previous research has shown that hiring IENs has been a strategy used by hospitals to address the nursing shortage. However, little research has focused on factors other than a shortage that could potentially influence hospitals' hiring decisions. The purpose of this study was to examine other factors such as competition and availability of resources that could potentially influence the hospitals' decision to hire IENs. RDT and Porter's five forces model were employed, in this paper, to test the hypotheses related to factors other than a shortage and their association with the decision to hire IENs in hospitals. Study results suggest that hospitals hire IENs as a strategy to meet their staffing needs in more competitive and diverse markets. 
Table 3. Logistic regression analysis

\begin{tabular}{|c|c|c|c|}
\hline & Variables & Odds Ratios & $p$-values \\
\hline Hypothesis 1 (Threat of new Entrants) & States with a Certificate-of-Need & 1.74 & .528 \\
\hline \multirow{7}{*}{$\begin{array}{l}\text { Hypothesis } 2 \text { (Bargaining power of the } \\
\text { Buyers) }\end{array}$} & Percent of foreign-born & 1.03 & .123 \\
\hline & Percent of Blacks ${ }^{\dagger}$ & 1.02 & $.003^{* *}$ \\
\hline & Percent of Hispanics ${ }^{\dagger}$ & 1.02 & $.080^{*}$ \\
\hline & Percent of American-Indians ${ }^{\dagger}$ & 1.05 & $.001^{* * *}$ \\
\hline & Percent of Asian / pacific Islanders ${ }^{\dagger}$ & 1.04 & .132 \\
\hline & Percent of Other races ${ }^{\dagger}$ & 1.02 & .974 \\
\hline & Medicare managed care penetration & 1.00 & .518 \\
\hline Hypothesis 3 (Threat of Substitutes) & Number of Ambulatory Surgery Centers & 1.00 & .634 \\
\hline $\begin{array}{l}\text { Hypothesis } 4 \text { (Bargaining Power of the } \\
\text { Suppliers) }\end{array}$ & Registered Nurses Per 1,000 population (lagged by one year) & 1.03 & .177 \\
\hline Hypothesis 5 (Intensity of Rivalry) & Competition (Market Concentration; Hirschman-Herfindahl Index) & 0.64 & $.032^{* *}$ \\
\hline \multirow{13}{*}{ Control Variables } & Percent of population 65 years and above & 0.96 & $.064^{*}$ \\
\hline & Unemployment Rate & 1.01 & .837 \\
\hline & Hospital Located in Metropolitan Area & 1.57 & $.022^{* *}$ \\
\hline & Not-for-profit ${ }^{\dagger \dagger}$ & 1.25 & .194 \\
\hline & Non-federal government ${ }^{\dagger \dagger}$ & 1.11 & 609 \\
\hline & System-affiliated Hospital & 1.29 & $.030^{* *}$ \\
\hline & Teaching Status & 1.13 & .594 \\
\hline & Size (Number of Staffed Beds) & 1.00 & $.001^{* * * *}$ \\
\hline & Proportion of Medicare Inpatient days & 2.46 & $.015^{* *}$ \\
\hline & Proportion of Medicaid Inpatient days & 2.01 & .113 \\
\hline & Northeast $^{\dagger+\dagger}$ & 0.13 & .127 \\
\hline & South $^{\dagger+\dagger}$ & 0.01 & $.001^{* * *}$ \\
\hline & West $^{\dagger+\dagger}$ & 0.08 & $.002^{* *}$ \\
\hline
\end{tabular}

Note. 4,116 (average number of hospitals / year observations, 2008-2012); ${ }^{\dagger}$ White (Reference); ${ }^{\dagger \dagger}$ For-profit (Reference); ${ }^{\dagger \dagger \dagger}$ Midwest census region (Reference); ${ }^{* * *} p$-value $<$ $.001 ;{ }^{* * *} p$-value $<.05 ;{ }^{*} p$-value $<.10$

According to Porter's five forces model, existing organizations in an industry compete with each other for critical resources in order to sustain their competitive advantage as well as to maintain or grow their market share. ${ }^{[23]}$ Findings of this study are consistent with Porter's model and show that hospitals compete for critical resources such as RNs. Therefore, they could potentially be trying to secure alternative sources of RNs by hiring IENs, to maintain their staffing levels, particularly in high RNs shortage areas. The positive association between higher market competition and the likelihood of hiring IENs provides evidence that hospitals employ strategies such as hiring IENs in response to competition. Hiring IENs may also be a strategy to lower staffing costs in hospitals with high RNs turnover ratios. Furthermore, to the extent that hiring IENs improves staffing levels, this may be a strategy to improve quality and ultimately improve financial performance. Previous research has shown that staffing levels are positively associated with quality of care, ${ }^{[19]}$ and higher quality of care has been associated with lower costs. ${ }^{[48]}$ As such, higher staffing levels may result in better financial performance, particularly in highly competitive markets. ${ }^{[21]}$

The study findings also support an association between bar- gaining power of the buyers and likelihood of hiring IENs. Hospitals serving ethnically diverse populations (higher percentage of Blacks, Hispanics, and American Indians) are more likely to hire IENs, which is consistent with the findings of Cho and colleagues. ${ }^{[18]}$ These findings could be attributed to the perceptions of hospital administrators related to the needs of the patient population they serve and the communities in which their hospitals operate. ${ }^{[18]}$ Hospitals may hire IENs not only as a strategy to address the nursing shortage but also to address the needs of the communities they serve, specifically if their patient population is ethnically diverse. To the extent that hiring IENs leads to more culturally competent care, this may result in better patient experiences. ${ }^{[49]}$

Slack resources also play an important role in the decision to hire IENs. Larger and system-affiliated hospitals have greater access to slack resources, and this allows them to invest in hiring IENs. Similarly, hospitals that see a greater number of Medicare patients are more likely to invest in hiring IENs than those with a higher proportion of Medicaid patients, since reimbursement from Medicare is higher than that from Medicaid. 
The study presents several limitations. First, the lack of detailed data on IEN staffing patterns limited the scope of this study. Since the question asking about hiring IENs is relative to the previous year and has a categorical response, it only conveys if the hospitals have IENs or not and if they are more, less or equal in number to those hired in the previous year. This response does not reflect the degree to which hospitals utilize IENs in terms of staffing intensity or staffing mix. Therefore, future research should focus on collecting detailed data related to the utilization of IENs in hospitals. Availability of detailed data on IENs, such as the proportion of IENs FTEs and total number of IENs employed by hospitals over the years, could allow for a more in-depth analysis of the hiring trends related to IENs. Second, this study was limited to examining the contextual factors associated with hiring IENs. Future studies should examine the association of hiring IENs with the hospitals' quality of care, costs, and financial performance. Furthermore, future research should evaluate the association of hiring IENs with patient satisfaction, particularly among hospitals operating in ethnically diverse markets.

IENs have become an integral part of the nursing workforce and could have a considerable impact on the quality of care and patient outcomes. Understanding the antecedents to hiring IENs by hospitals will help health care managers in making informed decisions related to hiring, managing and utilizing IENs to address their staffing needs. The findings of this study would also allow policy makers to evaluate the association of patient diversity with the hiring behavior of hospitals. Understanding the factors influencing the hospitals' decision to hire IENs, would facilitate formulation of more effective policies specifically focusing on facilitating or decreasing hiring of IENs by hospitals both as a strategy to address nursing shortages as well as to improve quality of care.

\section{REFERENCES}

[1] Hassmiller SB. Cozine M. Addressing the nurse shortage to improve the quality of patient care. Health Affairs. 2006; 25: 268-274. http://dx.doi.org/10.1377/hlthaff .25.1.268

[2] Chandra A, Willis WK. Importing nurses: Combating the nursing shortage in America. Hospital Topics. 2005; 83(2): 33-37. http://dx.doi.org/10.3200/HTPS.83.2.33-37

[3] U.S. Department of Health and Human Services. Projected supply, demand and shortages of registered nurses: 2000-2020. 2002.

[4] Buerhaus PI, Auerbach DI, Staiger DO. The recent surge in nurse employment: Causes and implications. Health Affairs. 2009; 28: 657-668. http://dx.doi.org/10.1377/hlthaff.28.4.w657

[5] Staiger DO, Auerbach DI, Buerhaus PI. Registered nurse labor supply and the recession - Are we in a bubble? New England Journal of Medicine. 2012; 366(16): 1463-1465. http://dx. doi .org/10. 1056/NEJMp1200641

[6] Keenan P, Kennedy JF. The nursing workforce shortage: Causes, consequences, proposed solutions. Issue brief: The Commonwealth fund. 2003; 169: 1-8. Available from: http://www.commonwealthfu nd.org/ /media/files/publications/issue-brief/2003/ apr/the-nursing-workforce-shortage--causes--conse quences--proposed-solutions/keenan_nursing-pdf .pdf

[7] Aiken LH, Xue Y, Clarke SP, et al. Supplemental nurse staffing in hospitals and quality of care. Journal of Nursing Administration. 2007; 37: 335-342. http://dx.doi.org/10.1097/01.NNA.00 00285119.53066 . ae

[8] Brush BL, Sochalski J, Berger AM. Imported care: Recruiting foreign nurses to U.S. health care facilities. Health Affairs. 2004; 23 : 78-87. http://dx.doi.org/10.1377/hlthaff.23.3.78

[9] Xu Y, Kwak C. Characteristics of internationally educated nurses in the United States. Nursing Economics. 2005; 23: 233-238. PMid: 16315653. Available from: http://fetch.mhsl.uab.edu/login?url=http://sear ch.proquest. com/docview/236935635? accountid=8240
[10] HRSA. U.S. Department of Health and Human Services: Health Resources and Services Administration. The registered nurse population: Findings from the 2008 National Sample Survey of Registered Nurses. 2010.

[11] Xu Y, Zaikina-Montgomery H, Shen JJ. Characteristics of internationally educated nurses in the United States: An update from the 2004 National Sample Survey of Registered Nurses. Nursing Economics. 2010; 28: 19-43. PMid: 20306875. Available from: http://fetch.mhsl.uab.edu/login?url=http://se arch . proquest . com/docview/236966037? accountid=8240

[12] Nichols BL, Gessert CE, Davis CR. Foreign-trained nurses in U.S healthcare delivery. American Journal of Public Health. 2007; 97(12): 2120. Author reply 2120-2121. http://dx.doi.org/10.2105/A JPH . 2007.121822

[13] Sochan A, Singh MD. Acculturation and socialization: Voices of internationally educated nurses in Ontario. International Nursing Review. 2007; 54: 130-136. http://dx.doi.org/10.1111/j.146 $6-7657.2007 .00564 . x$

[14] Davis CR, Nichols BL. Foreign-educated nurses and the changing U.S. nursing workforce. Nursing Administration Quarterly. 2002; 26: 43-51. http://dx.doi.org/10.1097/00006216-2002010 00-00006

[15] Jerdee AL. Recruiting foreign registered nurses: Charting the course Journal of Nursing Law. 2004; 9(3): 19-28.

[16] Xu Y, Kwak C. Comparative trend analysis of characteristics of internationally educated nurses and US educated nurses in the United States. International Nursing Review. 2007; 54: 78-84 http://dx.doi.org/10.1111/j.1466-7657.2007.00515.x

[17] Polsky D, Ross SJ, Brush BL, et al. Trends in characteristics and country of origin among foreign-trained nurses in the United States, 1990 and 2000. American Journal of Public Health. 2007; 97(5): 895-899. http://dx.doi.org/10.2105/AJPH. 2005.072330

[18] Cho SH, Masselink LE, Jones CB, et al. Internationally educated nurse hiring: Geographic distribution, community, and hospital 
characteristics. Nursing Economics. 2011; 29(6): 308-316. PMid: 22360105

[19] Needleman J, Buerhaus P, Mattke S, et al. Nurse-staffing levels and the quality of care in hospitals. New England Journal of Medicine. 2002; 346 (22): 1715-1722. http://dx.doi.org/10.1056/NEJ Msa012247

[20] Weech-Maldonado R, Meret-Hanke L, Neff M, et al. Nurse staffing patterns and quality of care in nursing homes. Health Care Management Review. 2004; 29(2): 107-116. http://dx.doi .org/10.10 97/00004010-200404000-00004

[21] Everhart D, Neff D, Al-Amin M, et al. The effects of nurse staffing on hospital financial performance: Competitive versus less competitive markets. Health Care Management Review. 2013; 38: 146-155. http://dx.doi.org/10.1097/HMR . Ob013e318257292b

[22] Pfeffer J, Salancik GR. The external control of organizations: A resource dependence approach. New York: Harper and Row Publishers; 1978

[23] Porter ME. Competitive strategy. New York: The Free Press; 1980.

[24] Aldrich HE. Organizations and environments. Englewood Cliffs, NJ: Prentice-Hall; 1979.

[25] Sinaiko AD, Rosenthal MB. Increased price transparency in health care-Challenges and potential effects. New England Journal of Medicine. 2011; 364(10): 891-894. http://dx.doi.org/10.10 56/NEJMp 1100041

[26] Starbuck WH. Organizations and their environments. In Marvin D. Dunnettet (ED). Handbook of industrial and organizational psychology. Chicago: Rand McNally; 1976. 1069-1123.

[27] Porter ME. Competitive advantage: Creating and sustaining superior performance. New York: The Free Press; 2008.

[28] Starkey KB, Weech-Maldonado R, Mor V. Market competition and quality of care in the nursing home industry. Journal of Health Care Finance. 2005; 32(1): 67-81. PMid: 18972979.

[29] Havighurst CC. Regulation of health facilities and services by certificate of need. Virginia Law Review. 1973; 59: 1143-1232. http://dx.doi.org/10.2307/1072049

[30] Buff MJ, Terrell TD. The Role of Third-Party Payers in Medical Cost Increases. Journal of American Physicians and Surgeons. 2014; 19(2).

[31] Barney J. Firm resources and sustained competitive advantage. Journal of Management. 1991; 17(1): 99-120. http://dx.doi.org/1 $0.1177 / 014920639101700108$

[32] MCOL. Managed care fact sheets: Managed care national statistics 2013. Retrieved March 5, 2013. Available from: http://www.mcol .com/managed_care_penetration

[33] MCOL. Managed care fact sheets: Managed care national statistics. 2011. Retrieved March 5, 2013. Available from: http://www.mcol .com/managed_care_penetration

[34] Al-Amin M, Housman M. Ambulatory surgery center and general hospital competition: Entry decisions and strategic choices. Health care Management Review. 2012; 37(3): 223-234. PMid: 22064474 http://dx.doi.org/10.1097/HMR.0b013e318235ed31

[35] Carey K, Burgess JF, Young GJ. Hospital competition and financial performance: The effects of ambulatory surgery centers. Health Eco- nomics. 2011; 20(5): 571-581. PMid: 21433218. http://dx.doi . org/10.1002/hec. 1617

[36] Medicare Payment Advisory Commission (Med PAC). Report to the Congress: Medicare payment policy. March 2004. Retrieved March 5, 2013. Available from: http://www.medpac.gov/publicati ons/congressional_reports/Mar04_Table_Contents.pdf

[37] Kusserow RP. Patient satisfaction with outpatient surgery. A national survey of Medicare beneficiaries. U.S. department of Health and Human Services. 1989. Retrieved March 5, 2013. Available from: ht tps://oig.hhs.gov/oei/reports/oei-09-88-01002.pdf

[38] Munnich EL, Parente ST. Costs and benefits of competing health care providers: Trade-offs in the outpatient surgery market. 2013.

[39] Chukmaitov A, Devers K, Harless DW, et al. Strategy, structure, and patient quality outcomes in ambulatory surgery centers (1997-2004). Medical Care Research and Review. 2010. http://dx.doi .org/1 $0.1177 / 1077558710378523$

[40] American Association of College of Nursing. Nursing shortage factsheet. 2011. Retrieved March 5, 2012. Available from: http://ww w. aacn.nche.edu/media-relations/NrsgShortageFS.pdf

[41] Banaszak-Holl J, Zinn JS, Mor V. The impact of market and organizational characteristics on nursing care facility service innovation: A resource dependence perspective. Health Services Research. 1996; 31: 97-117. PMid: 8617612

[42] American Hospital Association. AHA annual survey database fiscal year 2010. 2012. Retrieved March 5, 2012. Available from: http:// www . ahadataviewer.com/book-cd-products/AHA-Survey/

[43] HRSA. U.S. Department of Health and Human Services: Health Resources and Services Administration. National county-level health resources information database: Overview. 2011. Retrieved March 5 , 2012. Available from: http://AHRF.hrsa.gov/overview.htm

[44] National Conference of State Legislatures (NCSL). CON Certificate-of-need state laws. 2012. Retrieved March 10, 2013. Available from: http://www.ncsl.org/issues-research/health /con-certificate-of-need-state-laws .aspx

[45] Mark BA, Harless DW. Nurse staffing, mortality, and length of stay in for-profit and not-for-profit hospitals. Inquiry. 2007; 44: 167-186. http://dx.doi.org/10.5034/inquiryjrnl_44.2.167

[46] Mick SS, Lee SY. The safety-net role of international medical graduates. Health Affairs. 1997; 16: 141-150. http://dx.doi.org/10. 1377/hlthaff.16.4.141

[47] Seago JA, Spetz J, Mitchell S. Nurse staffing and hospital ownership in California. Journal of Nursing Administration. 2004; 34: 228-237. http://dx.doi.org/10.1097/00005110-200405000-00006

[48] Weech-Maldonado R, Neff G, Mor V. Does quality of care lead to better financial performance?: the case of the nursing home industry. Health Care Management Review. 2003; 28(3): 201-216. PMid: 12940343. http://dx.doi.org/10.1097/00004010-2 00307000-00002

[49] Weech-Maldonado R, Elliott MN, Pradhan R, et al. Can hospital cultural competency reduce disparities in patient experiences with care?. Medical care. 2012; 50: S48. PMid: 23064277. http: //dx.doi.org/10.1097/MLR.0b013e3182610ad1 